\title{
Predicting the impact of border control on malaria transmission: a simulated focal screen and treat campaign
}

\author{
Sheetal P Silal ${ }^{1 *}$, Francesca Little ${ }^{1}$, Karen I Barnes ${ }^{2}$ and Lisa J White ${ }^{3,4}$
}

\begin{abstract}
Background: South Africa is one of many countries committed to malaria elimination with a target of 2018 and all malaria-endemic provinces, including Mpumalanga, are increasing efforts towards this ambitious goal. The reduction of imported infections is a vital element of an elimination strategy, particularly if a country is already experiencing high levels of imported infections. Border control of malaria is one tool that may be considered.

Methods: A metapopulation, non-linear stochastic ordinary differential equation model is used to simulate malaria transmission in Mpumalanga and Maputo province, Mozambique (the source of the majority of imported infections) to predict the impact of a focal screen and treat campaign at the Mpumalanga-Maputo border. This campaign is simulated by nesting an individual-based model for the focal screen and treat campaign within the metapopulation transmission model.

Results: The model predicts that such a campaign, simulated for different levels of resources, coverage and take-up rates with a variety of screening tools, will not eliminate malaria on its own, but will reduce transmission substantially. Making the campaign mandatory decreases transmission further though sub-patent infections are likely to remain undetected if the diagnostic tool is not adequately sensitive. Replacing screening and treating with mass drug administration results in substantially larger decreases as all (including sub-patent) infections are treated before movement into Mpumalanga.

Conclusions: The reduction of imported cases will be vital to any future malaria control or elimination strategy. This simulation predicts that FSAT at the Mpumalanga-Maputo border will be unable to eliminate local malaria on its own, but may still play a key role in detecting and treating imported infections before they enter the country. Thus FSAT may form part of an integrated elimination strategy where a variety of interventions are employed together to achieve malaria elimination.
\end{abstract}

Keywords: Imported infections, Malaria, Elimination, Focal screen and treat

\section{Background}

Since the call for renewed efforts towards global malaria eradication in 2007, it has been acknowledged that new tools will be required to achieve this ambitious goal [1-5]. Drugs will need to be developed for a variety of purposes including use in elimination-focused strategies like mass drug administration (MDA) and mass

\footnotetext{
*Correspondence: Sheetal.Silal@uct.ac.za

1 Department of Statistical Sciences, University of Cape Town,

Rondebosch, Cape Town 7700, South Africa

Full list of author information is available at the end of the article
}

screen and treat (MSAT) campaigns, prophylactic use and transmission prevention [3]. New insecticides and formulations will need to be developed considering varied vector biology and habits [5]. Importantly, diagnostic tools that are easily implemented with increased sensitivity and a decreased processing time will be necessary to quickly and successfully diagnose both patent and sub-patent infections [2]. This is particularly important as the impact of MSAT is dependent on the screening tool. South Africa is one of many countries committed to achieving malaria elimination with a target set at 2018 
and all malaria-endemic provinces, including Mpumalanga province, are increasing efforts towards this ambitious goal. A malaria elimination strategy should aim to interrupt the transmission cycle and prevent it from being re-established. A successful interruption of malaria transmission ideally requires three elements: (1) the elimination of the vector, (2) the blockade of imported infections and (3) the reduction of these imported infections at their source [6]. It is unlikely that the first element will be achieved absolutely [7]. It is possible that the second element can be achieved if imported infections are identified and treated before they can contribute to the local infectious reservoir and regional collaboration is key to the success of the third element [6]. Silal et al. have simulated interventions in Mpumalanga using mathematical modelling techniques aimed towards elements (1) and (3) $[8,9]$. The reduction of imported infections was dealt with at a broad level through the simulation of a focal screen and treat (FSAT) campaign at the MpumalangaMaputo border in Silal et al. [9]. This paper focuses in more detail on the proposed FSAT campaign at the Mpumalanga-Maputo border using a hybrid metapopulation differential equation and individual based modelling (DE-IBM) approach.

Malaria in Mpumalanga has been documented extensively [10-18]. Currently, malaria transmission occurs primarily in Ehlanzeni District on the border of both
Maputo in Mozambique and Swaziland. The five municipalities in Ehlanzeni District are most affected by malaria in the province (Figure 1). The sharp decline in malaria incidence and malaria-related deaths in the province between 2002 and 2012 has been attributed to a series of policy interventions including intense vector control through indoor residual spraying (IRS), the introduction of artemisinin-based combination therapy (ACT) policy of artesunate plus sulphadoxine-pyremethamine in 2003, followed by artemether-lumefantrine (AL) in 2006 and the Lubombo Spatial Development cross-border Initiative (LSDI) between Mozambique, Swaziland and South Africa [12]. The LSDI malaria programme focused its activities primarily in Maputo Province in Mozambique and was later extended to Gaza Province resulting in substantial decreases in prevalence [19]. However the programme was terminated early in September 2010 and the resultant reduced IRS in Maputo thereafter correlates with increased malaria incidence observed from 2011 [20]. Between 2002 and 2012, 40650 cases were notified, with the proportion of imported cases increasing from $39 \%$ in 2002 to $87 \%$ in 2012 . Of the cases imported in 2012, 13\% were sourced in South Africa and 85\% were sourced from Mozambique (with the remaining 2\% sourced from other African and Asian countries).

Compartment models and their applications in malaria in particular, have a history that spans more than 100

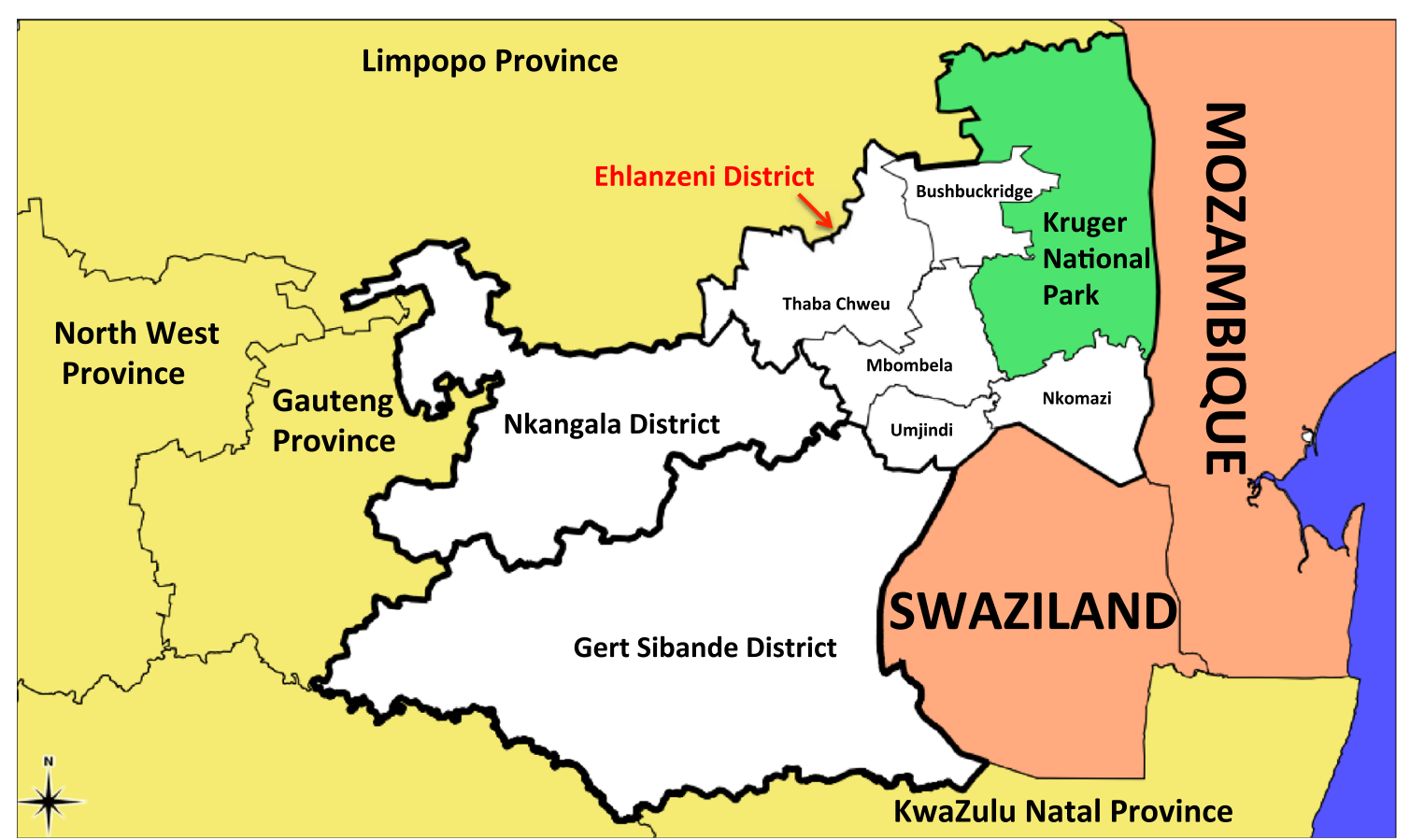

Figure 1 A map of Mpumalanga Province in relation to Mozambique and Swaziland [source: Mpumalanga Malaria Elimination Programme (unpublished)]. 
years [21]. Increases in computing power have led to the increased use of individual based models in recent years [22]. Metapopulation compartment models are an extension of compartment models where the population under consideration is sub-divided into patches. A compartment model is run in each patch and the patches are linked together, usually along geographical lines [23]. There have been several metapopulation compartment model applications in malaria [24-31]. There have also been several applications of IBMs in malaria [32-35]. With regards to screening and treating, Crowell et al. modelled the cost effectiveness of MSAT as a disease reduction tool in various sub-Saharan African settings [36]. MSAT was found to be effective in medium and high transmission settings and was recommended to complement and not replace interventions like active case detection and vector control. Griffin et al. [33] modelled the impact of MSAT in an African setting at various transmission intensities and found MSAT to be a complement to insecticide treated nets (ITN) usage and IRS. Maude et al. [37] modelled the impact of MSAT in the face of artemisinin resistance and found that while MSAT was able to reduce artemisinin resistant infections in the short term, it was unable to eliminate them. White et al. [38] modelled the impact of MSAT in a comparison of simple and complex mathematical models. Applications of mathematical modelling of malaria in Mpumalanga have included a climate-based fuzzy distribution model [39], an eco-hydrological model for malaria outbreaks [40] and a cluster detection model [41]. Silal et al. [8] investigated the impact of FSAT and other interventions to achieve malaria elimination in Mpumalanga using a population level compartment model and Silal et al. [9] extended this application to a metapopulation model of the five municipalities in Ehlanzeni district and Maputo province. The hybrid metapopulation DE-IBM model presented in this paper is developed to simulate the impact of FSAT at the Mpumalanga-Maputo border as a means to decrease the inflow of imported infections. This is the first model designed for this purpose in $\mathrm{Mpu}-$ malanga and the first to do so since the call for malaria elimination in South Africa.

\section{Methods}

\section{Transmission model}

The model presented in this paper is based on the metapopulation model described in Silal et al. [9]. The malaria transmission model has a metapopulation structure where the population of interest is divided into discrete patches under the assumption that individuals in these patches exhibit homogenous behaviour. Rather than modelling transmission in these patches in isolation, a metapopulation structure allows for transmission in a particular patch to be influenced by transmission in other patches. In this study, the area of interest is divided into six geographical patches: five patches for the five municipalities in Ehlanzeni District [Thaba Chewu (TC), Mbombela (MB), Umjindi (UJ), Nkomazi (NK) and Bushbuckridge (BB)] and one patch for Maputo province (MP). Each patch is further divided into three subpatches representing (1) the local population currently in the patch, (2) the local population having returned from travel to a foreign place (Maputo, if the patch is South African and vice versa) and (3) the population from the foreign place currently in the patch (Figure $2 b$ ). A malaria transmission model is developed for each subpatch where the sub-patch population is divided into six compartments representing the population susceptible

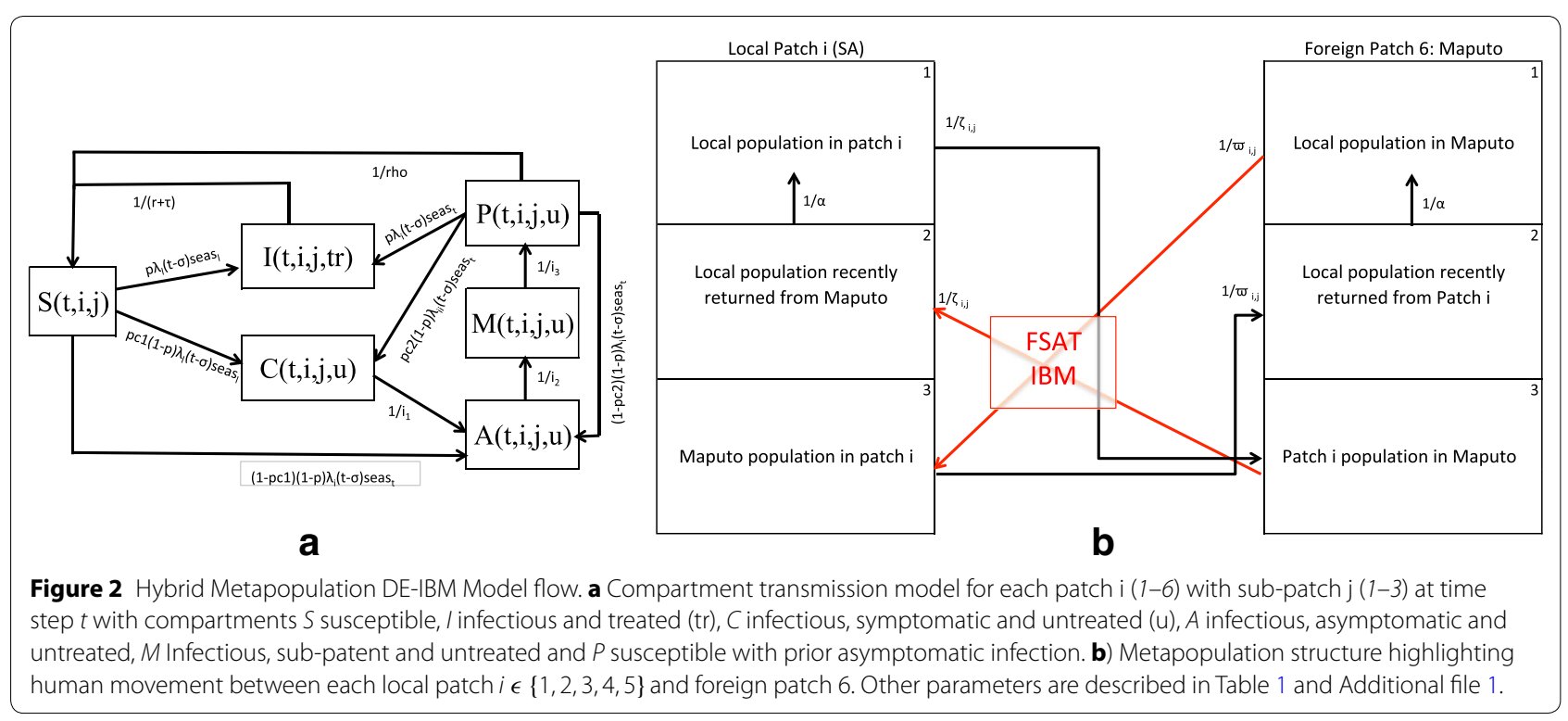


to malaria (S), the population at the infectious stage that receives treatment (I), the untreated symptomatic population at the infectious stage $(C)$, the untreated asymptomatic population at the infectious stage (A), the untreated asymptomatic, sub-patent $(<100$ parasites $/ \mu \mathrm{L})$ infectious population $(\mathrm{M})$ and the population susceptible to malaria, but with prior asymptomatic infection (P) (Figure 2a). The liver and blood stages of the infection are incorporated as a delay in the flow between the susceptible and infectious stage compartments. Flows between compartments are governed by parameters described in Table 1. While the seasonal nature of transmission is incorporated in the model using forcing functions, the mosquito population is not modelled directly as it is assumed that the mosquito dynamics operate on a faster time-scale than the human dynamics and hence the mosquito population may be considered to be at equilibrium with respect to changes in the human population [42]. Transmission is modelled in weekly time steps.

Human movements between patches are modelled in two ways. Local travel may occur between the five Mpumalanga patches (from all five compartments in all three sub-patches). Foreign travel may occur between the Maputo patch and the five Mpumalanga patches (from all five compartments) as illustrated in Figure $2 b$. These movements are inversely weighted by distance so that movements between patches that are closer together are more likely than movements between patches that are further apart. A full description of the metapopulation transmission model is presented in Additional file 1.

\section{FSAT model}

Figure $2 \mathrm{~b}$ shows that only movement of the local Mpumalanga population returning from Maputo (patch 6, sub-patch 3 to patches $1-5$, sub-patch 2 ) and the foreign population travelling to Mpumalanga from Maputo (patch 6, sub-patch 1 to patches 1-5, sub-patch 3) are subject to the FSAT campaign as the purpose of the campaign is to prevent infections from entering Mpumalanga. The FSAT model has an individual-based model structure so that individual characteristics of the participants may be taken into account. Figure 3 depicts the algorithm applied to individuals in the FSAT model. The flow of local and foreign populations from Maputo into Mpumalanga at each time step (week) is captured and geographical destination patch, the sub-patch and disease status (susceptible, infectious, sub-patent etc) are stored for each individual in that flow. The first step is to simulate a parasite count for each individual dependent on their disease status. The log-normal distribution was selected with distribution parameters in Table 2 as it captures the skewness of parasite count distribution. To test the impact of take-up proportion, the campaign is modelled as being optional. Should an individual not wish to be part of the campaign, their disease status is maintained and the simulation is stopped. Depending on the diagnostic tool used, the processing times and hence the number of tests able to be performed per week will differ. Should capacity be available and an individual agrees to participate in the campaign, the individual is screened. A positive screen occurs if the individual's simulated parasite load is greater than the detection threshold of the diagnostic tool in use. A positive screen will result in the individual being treated. As the treatment is likely to be a multiple-dose regimen, there is a chance that the individual may not adhere to the full course and may run the risk of failing treatment. In the event of successful treatment, the individual's disease status is updated (e.g. Infectious to "Infectious having received FSAT" where the individual is cured from malaria at a rate of recovery dependent on the parasite clearance time of the drug) and the simulation stops. The model parameters governing this IBM algorithm are displayed in Table 2.

\section{Hybrid metapopulation DE-IBM model}

The metapopulation DE model and the IBM model are linked such that the IBM model is nested in the DE model. At each time step, the DE model generates flows of a population that leave one compartment and enter another compartment (in the various sub-patches and patches). The IBM model takes the flow value at each time step once it has been negated from a compartment, discretises it into individuals in a population, executes the IBM algorithm, re-groups the individuals back into a population flow, and adds the flow to its destination compartment. In this application, only the flows of local and foreign people entering the five Mpumalanga patches from Maputo are interrupted to perform FSAT using the IBM model. Further details on this hybrid modelling approach are available in the Additional file 1.

\section{Data fitting}

The metapopulation transmission model is fitted to weekly case notification data from Mpumalanga and Maputo Province from 2002 to 2008, and then validated with data from 2009 to 2012. Ethical approval for use of this secondary data was obtained from the Mpumalanga Department of Health and the University of Cape Town Human Research Ethics Committee. The Mpumalanga case data displays a characteristic triple peaked pattern in the malaria season with peaks occurring in September/October, December/January and April/May while the Maputo Province malaria season exhibited peaks in December and April only [10]. The seasonal forcing functions, used to determine seasonal variation in transmission, for the six patches are derived from the data using 


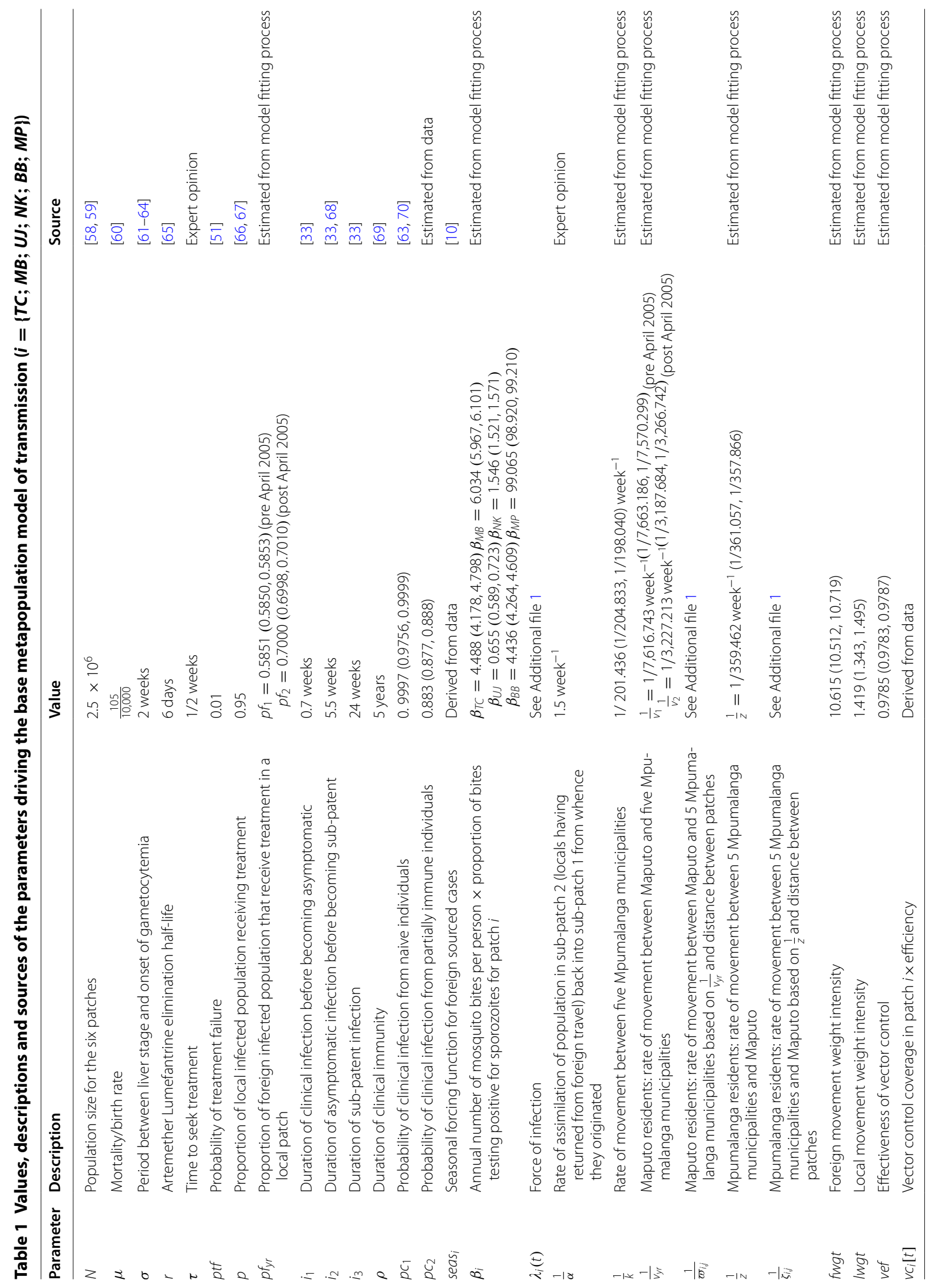




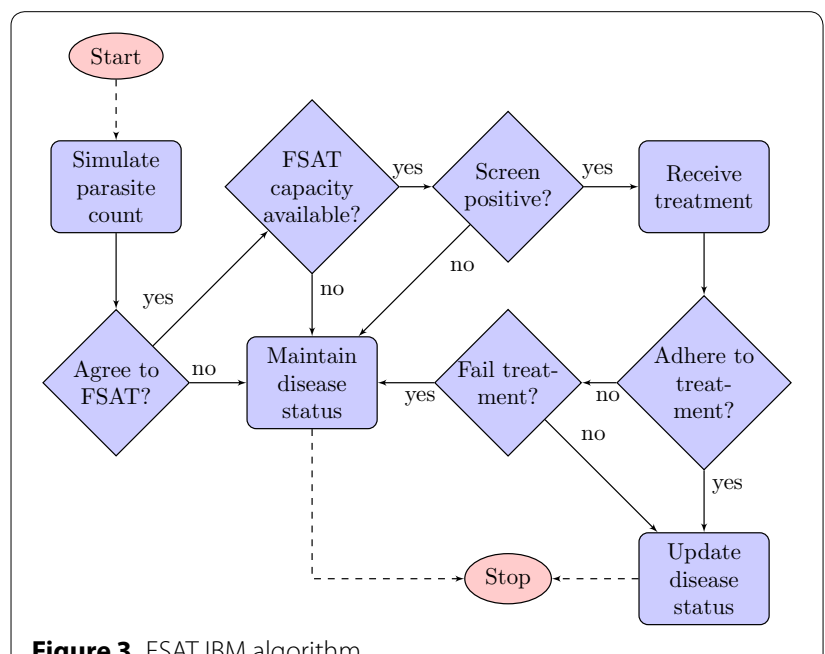

Figure 3 FSAT IBM algorithm.

seasonal decomposition of time series by LOESS (STL) methods for extracting time series components [43]. ACT drug therapy and the impact of IRS implemented between 2002 and 2008 are also included in the model. In order to reach a steady state the model is run deterministically from 1990 before being fitted to data from 2002 . The model output (predicted weekly treated cases) is fitted to the data from 2002 to 2008 using the maximum likelihood approach by assuming an underlying Poisson distribution with rate $\lambda$ as the number of treated cases per week. Several parameters as detailed in Table 1 are estimated through the data fitting process using the population-based global search algorithm of particle swarm optimisation [44, 45]. The model with the estimated parameter values is then validated with a further 3 years of data (2009-2012). A full description of the data fitting method is presented in Additional file 1. All model development, fitting and subsequent analysis was performed in R v3.02 [46]. The particle swarm optimisation routine was performed using the R package hydroPSO v0.3-3 [47, 48].

\section{Simulated FSAT}

An FSAT campaign is tested on a stochastic version of the fitted model; the same intervention is applied to multiple model runs such that its impact on local infections can be described with a mean effect and a 95\% confidence interval. Stochastic uncertainty and parameter sensitivity has been accounted for as follows. The model is run stochastically by treating each flow between compartments at each time point $t$ as a random realisation of a Poisson process with rate $\lambda$, the deterministic flow value at that time, and by simulating the parameter values uniformly from their $95 \%$ confidence intervals. The predicted impact of an FSAT campaign at the MpumalangaMaputo border is presented with respect to coverage levels, thresholds of detection, take-up proportions, target levels and typical diagnostic tools. To facilitate accurate comparison of coverage levels, targets, thresholds and diagnostic tools, the take-up proportion of FSAT is fixed at $100 \%$. Take-up proportion itself is explored at low, intermediate and high levels. The FSAT campaign is assumed to run for $8 \mathrm{~h}$ a day, seven days a week with a maximum of three tests being conducted simultaneously. This number of simultaneous tests is also considered at different levels in the simulation. As malaria elimination is defined by the World Health Organisation as zero incidence of locally contracted cases, the impact of the simulated FSAT campaign is measured as the decrease in local

Table 2 Values, descriptions and sources of the parameters driving the FSAT Individual Based Model

\begin{tabular}{|c|c|c|c|}
\hline Parameter & Description & Value & Source \\
\hline fson & Focal Screen and Treat Switch & Binary & \\
\hline \multirow[t]{2}{*}{ cov } & FSAT coverage & $25 ; 50 ; 75 ; 100 \%$ & Values to be tested \\
\hline & Baseline FSAT coverage & $70 \%$ & Assumed \\
\hline fsprop $[t]$ & Proportion Screened and Treated through Border Control & fson $\times$ cov & \\
\hline opt & Take-up proportion for FSAT & $25 ; 50 ; 75 ; 100 \%$ & Values to be tested \\
\hline$a d h$ & Probability of adherance & 0.90 & {$[51]$} \\
\hline fail & Probability of treatment failure & 0.01 & {$[51]$} \\
\hline rep & Number of screens tests performed simultaneously & 3 & Assumed \\
\hline$\mu_{C}$ & Geometric mean of log-normal parasite distribution for clinical infections & 25,000 & {$[71,72]$} \\
\hline$\sigma_{C}$ & Log standard deviation of log-normal parasite distribution for clinical infections & 1.3 & {$[71,72]$} \\
\hline$\mu_{A}$ & Geometric mean of log-normal parasite distribution for asymptomatic infections & 1,000 & {$[71,73]$} \\
\hline$\sigma_{A}$ & Log standard deviation of log-normal parasite distribution for asymptomatic infections & 1.5 & {$[71,73]$} \\
\hline$\mu_{S}$ & Geometric mean of log-normal parasite distribution for sub-patent infections & 50 & {$[55]$} \\
\hline$\sigma_{S}$ & Log standard deviation of log-normal parasite distribution for sub-patent infections & 0.75 & Assumed \\
\hline
\end{tabular}


infections as result of the campaign [7]. This impact is a function of the change in onward transmission resulting from fewer imported infections entering Mpumalanga (due to FSAT). All results are compared to the base case of no FSAT, depicted in black in all figures. Each scenario was run 450 times so that results presented are the mean local infections per week with a $95 \%$ confidence interval shaded around the mean. In many cases, the shading is not visible due to either narrow confidence intervals or a low resolution y-axis.

\section{Diagnostic tools}

Diagnosing malaria at a border point ideally requires a diagnostic tool that is both sensitive, specific and has a short processing time. Several tools have been considered for this simulation (Table 3). The Rapid Diagnostic Test (RDT) currently in use at South African public health facilities has a theoretical detection threshold of 200 parasites $/ \mu \mathrm{L}$ and a maximum processing time of 20 min. Microscopy in experienced hands may exhibit a sensitivity of 50 parasites/ $\mu \mathrm{L}$ but is more likely to have a sensitivity in the region of 100 parasites/ $\mu \mathrm{L}$. Real-time quantitative polymerase chain reaction (qPCR) and loop-mediated isothermal DNA amplification (LAMP) are very sensitive tools with qPCR needing sophisticated equipment for a processing time of $3 \mathrm{~h}$. LAMP on the other hand is a less complex technique with a 1 $\mathrm{h}$ processing time [49]. These diagnostic tools are also compared to a highly sensitive hypothetical RDT with a standard process time of $20 \mathrm{~min}$ and a detection threshold of 5 parasites $/ \mu \mathrm{L}$.

\section{Results}

The estimation of parameters through data fitting is presented first followed by the results of a simulated FSAT campaign at varied coverage levels, target levels and thresholds of detection.

\section{Estimation of parameters through data-fitting}

Weekly case data for the five Mpumalanga patches and Maputo (black) along with the model output from the data-fitting process (red) and predicted model output for 2009 to 2012 (blue) is shown in Figure 4. Figure 4 is a summation of the data fitting results in each patch, as data was fitted to each sub-patch simultaneously. Both the peak and timing of the malaria season in Ehlanzeni District and Maputo Province are captured well by the model prediction and the uncertainty range. Additional file 1 contains more detailed output from the datafitting procedure. The parameters estimated through data-fitting and other parameters driving the transmission model are presented in Table 1. There are two rates each for the foreign treatment proportion and the rate of foreign movement. This is due to the waiver of short stay visa requirements between Mozambique and South Africa in April 2005, resulting in increased cross-border movement [50].

\section{Diagnostic tools}

The model predicts that at a baseline FSAT coverage of $70 \%$, microscopy and qPCR do not substantially decrease local infections due to their long processing time (Figure 5). LAMP and the RDT with a detection threshold of 200 parasites $/ \mu \mathrm{L}$ are predicted to lead to larger decreases in local infections. LAMP is more likely to detect asymptomatic and sub-patent infections than the RDT, but the three times longer turnaround time results in only a third of the tests being performed compared to the RDT. The hypothetical RDT that is as sensitive as LAMP is predicted to perform the best as it combines a high sensitivity with a short processing time.

\section{Coverage, detection thresholds, take-up proportions and target levels}

Coverage levels refer to the proportion of cross-border movements reached by the FSAT campaign. This proportion is generally less than $100 \%$ to account for other forms of entry into the province e.g. illegal entry. FSAT at various coverage levels is simulated using the characteristics of the RDT currently in use in South Africa (theoretical detection threshold of 200 parasites $/ \mu \mathrm{L}$ and a process time of $20 \mathrm{~min}$. Figure $6(1)$ shows that even at $25 \%$ coverage, a substantial decrease in local infections is predicted. The marginal impact on local infections decreases to the point where local infections at 75 and $100 \%$ FSAT coverage are non-distinguishable with overlapping confidence

Table 3 Descriptions of diagnostic tools used in FSAT model

\begin{tabular}{lllll}
\hline Tool & $\begin{array}{l}\text { Detection threshold } \\
\text { (parasites/ } \mathbf{\mu L})\end{array}$ & Process time $\mathbf{( h )}$ & $\begin{array}{l}\text { Target per week } \\
\text { (tests per/h } \mathbf{3} \text { reps } \mathbf{x} \mathbf{8} \mathbf{h} \times \mathbf{7} \text { days) }\end{array}$ & Source \\
\hline RDT & 200 & 0.33 & 504 & {$[49]$} \\
Microscopy & 100 & 2.25 & 75 & Expert opinion, [49] \\
qPCR & 1 & 3 & 63 & {$[49]$} \\
LAMP & 5 & 1 & 168 & {$[74,75]$} \\
Hypothetical RDT & 5 & 0.33 & 504 & \\
\hline
\end{tabular}




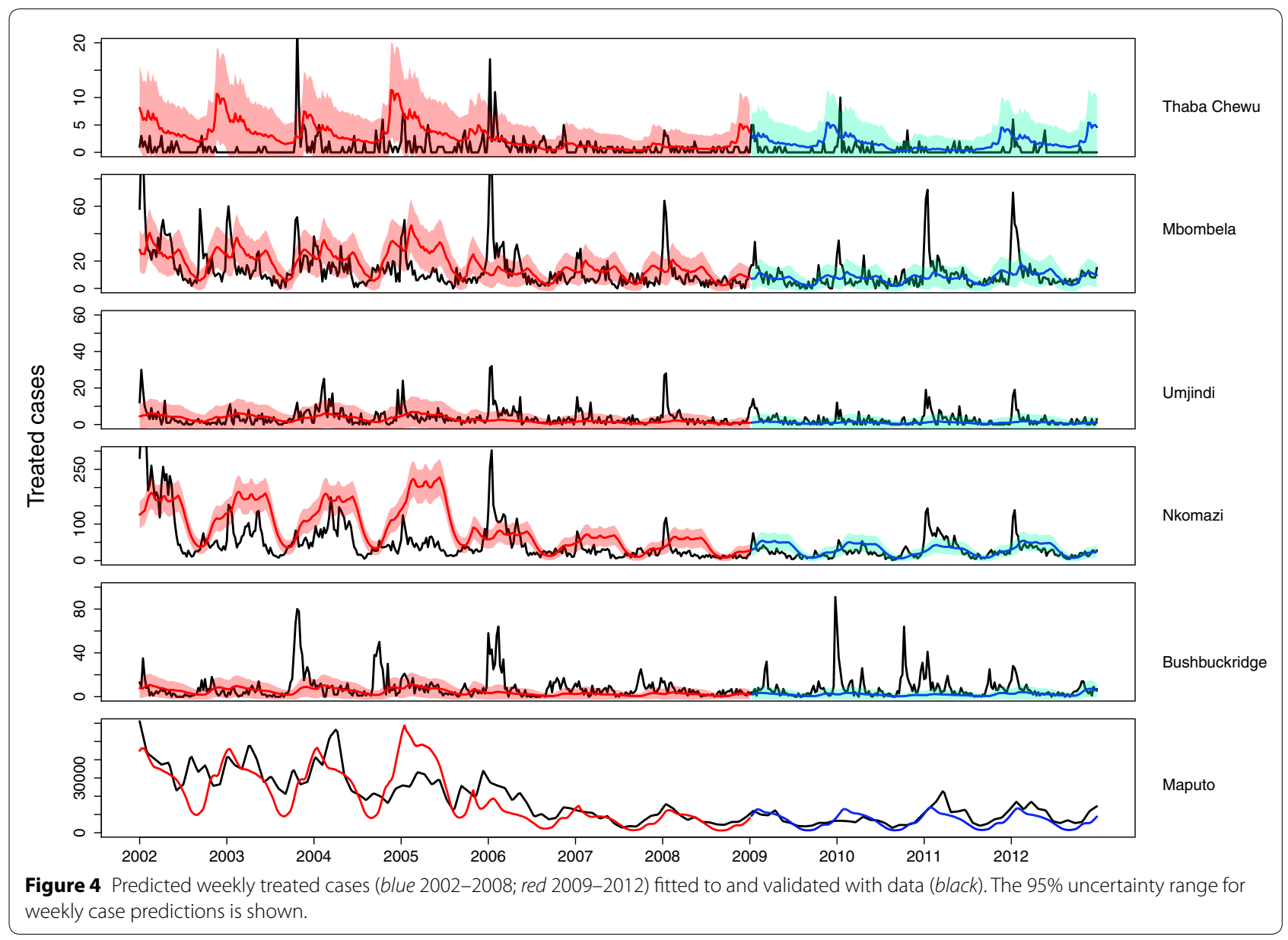

intervals for the expected decrease in local infections. This occurs because though coverage may be very high, infections with less than 200 parasites $/ \mu \mathrm{L}$ will remain undetected by a standard RDT.

In simulating the impact of detection thresholds alone, coverage is kept at its baseline value of $70 \%$. Figure 6(2) shows that the predicted impact on local infections of using an RDT at any threshold is substantial. The greatest decrease in local infections is predicted with the most sensitive RDT. The impact of take-up proportion is such that a low proportion of only $25 \%$ does not substantially decrease local infections compared to the extreme of $100 \%$ take-up i.e. mandatory participation (Figure 6(3)). The local infections predicted by mandatory participation may be further decreased if a more sensitive tool was used, or coverage was higher. If mandatory participation is a viable option, a government could consider a mass drug administration instead of FSAT. Figure 6(4) suggests that at even $50 \%$ coverage, the impact of MDA is higher than FSAT at 100\% coverage as sub-patent infections are being captured by the intervention. A baseline assumption is that three screenings may be performed simultaneously. If this capacity is increased, the number of tests that may be performed per week will also increase. Comparing different weekly target levels suggests that any target below 250 people is not predicted to substantially decrease local infections (Figure 6(5)).

A sensitivity analysis was conducted to assess the effect of varying coverage, detection thresholds, take-up proportions, adherence and target levels simultaneously in addition to the one-at-a-time analysis conducted above. The decrease in local infections was measured for each combination of factors and a linear model regressing these five factors on the decrease in local infections was fitted to assess sensitivity. The standardised regression coefficients in Table 4 suggest that holding the other factors constant, detection threshold in an FSAT campaign has the largest absolute impact on decreasing local infections, followed by coverage achieved, take-up proportion and target level. This is in line with Figures 5 and 6 where the largest decreases were achieved for the most sensitive diagnostic tool. Adherence was the only factor to have a non-significant impact on the decrease in local infections, primarily because the probability of treatment failure 

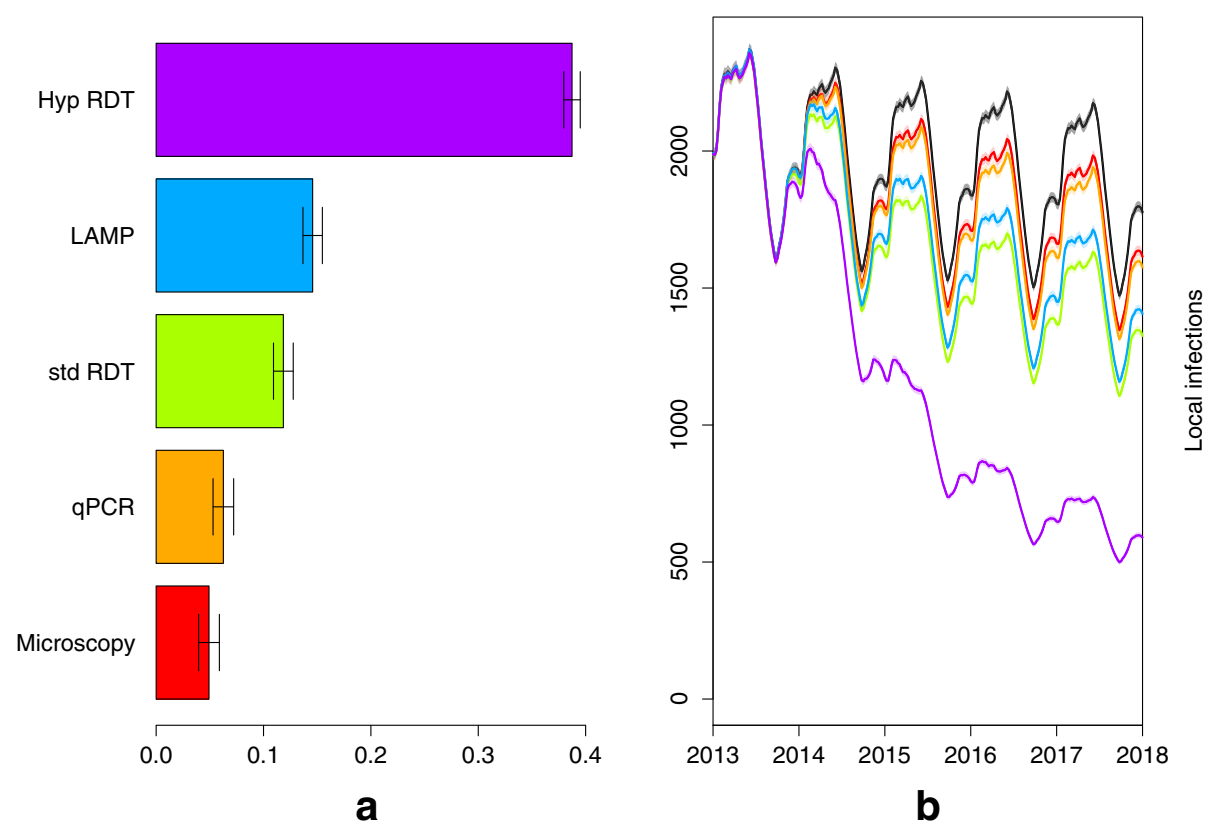

Figure 5 Predicted impact due to FSAT between 2014 and 2018 using the following diagnostic tools: microscopy (red), qPCR (orange), RDT (green), LAMP (blue) and a hypothetical RDT (purple). a Shows the percentage decrease in local infections due to the FSAT and $\mathbf{b}$ shows the impact of FSAT on local infections in Ehlanzeni district through time compared to the base case of no interventions (black).

assumed in this study is only 0.01 [51]. With the rise of artemisinin resistance, it is likely that the probability of treatment failure will increase, and adherence will be of greater importance than this simulation study has shown.

\section{Discussion}

This paper presented a hybrid DE-IBM model where a metapopulation level, non-linear stochastic ordinary differential equation model was used to simulate malaria transmission in Mpumalanga and Maputo so that Individual-Based Modelling techniques may be used to predict the impact of FSAT at the Mpumalanga-Maputo border. The model has predicted that the various scenarios of FSAT considered in this paper will decrease the number of local infections, but not eliminate malaria. Testing FSAT at various levels of coverage, take-up, detection thresholds and targets suggested that decreases in local infections are most sensitive to the detection threshold, and hence the diagnostic tool used, followed by coverage achieved. Von Seidlein [52] lists both the inability of FSAT to detect and treat all infections (using RDTs), and hence the inability to prevent reinfection as reasons why screening and treating failed in trials conducted at a school level [53]. This study and those discussed earlier suggest that as long as the reservoir of sub-patent infections endures, FSAT on its own will not be able to eliminate malaria. The model has predicted through various scenarios of FSAT, that it may still be successful in reducing local malaria incidence, even if it cannot reduce it to zero. In this manner, FSAT may still form part of an integrated elimination strategy where a variety of interventions are employed together to achieve malaria elimination.

In the last decade, a policy shift to ACT, source reduction through vector control in Mozambique in the LSDI malaria programme and a strong IRS strategy have contributed to decreasing malaria prevalence in Mpumalanga to the low levels experienced today. In shifting focus from control to elimination, the goal to interrupt transmission and prevent its reestablishment implies that a "more of the same" approach will not work [6]. The early termination of the LSDI programme and the associated subsequent rise in cases in Maputo Province and Mpumalanga demonstrate the importance of regional collaboration and urgency to collaborate further. Silal et al. assessed the impact of source reduction in Maputo on malaria incidence in Mpumalanga using a metapopulation model of transmission [9]. That model predicted that the largest decrease in local infections was achieved when source-reducing interventions were simulated. Of the three ideal elements of an elimination strategy highlighted in the introduction of this paper, the prevention of imported infections is not addressed by a strong IRS focus as IRS will limit onward transmission of all infections but is not targeted at imported infections. The implementation of FSAT at the border is one strategy to 


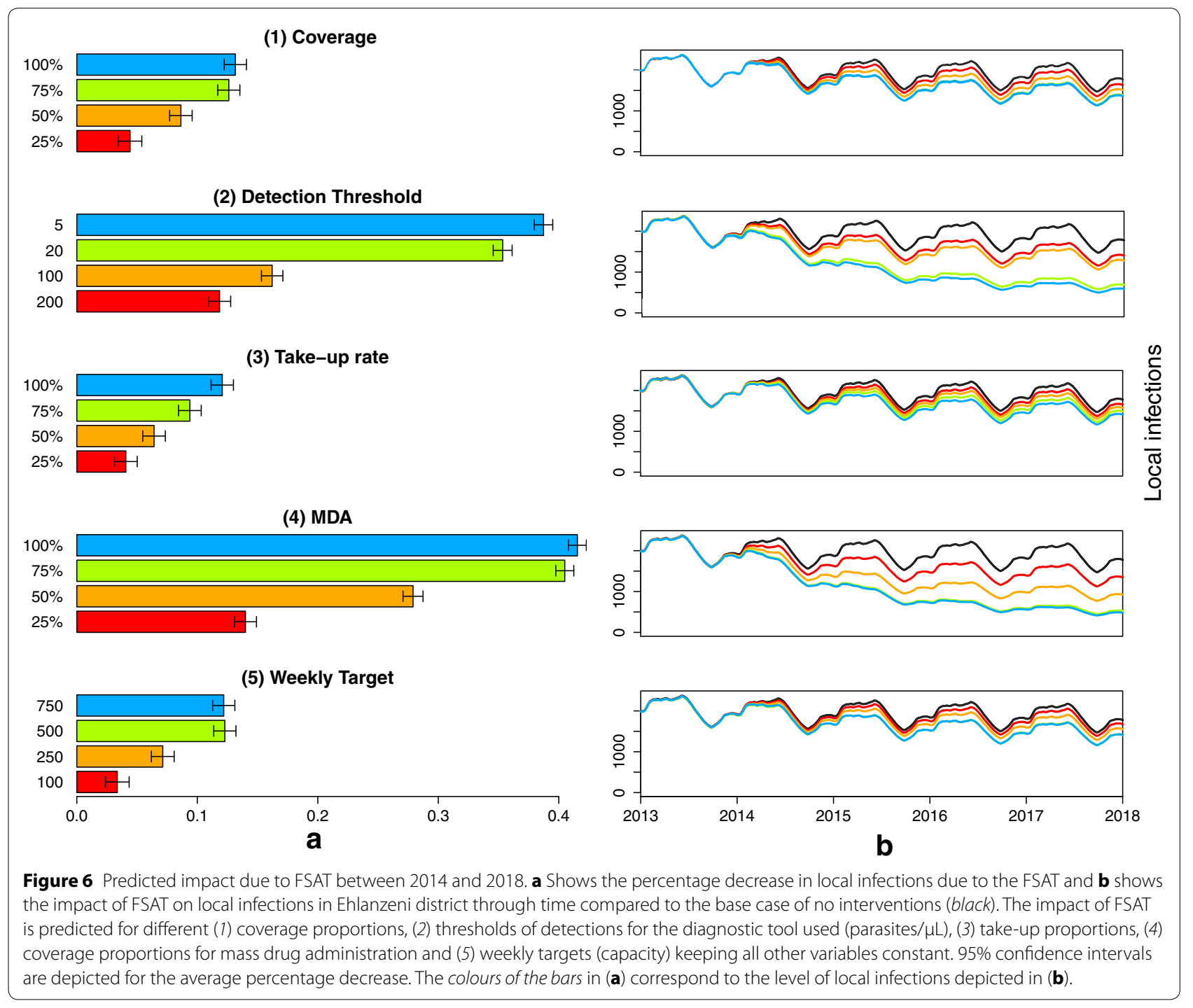

Table 4 Sensitivity analysis of factors assessed in FSAT model

\begin{tabular}{lcl}
\hline Factor & $\begin{array}{l}\text { Standardised } \\
\text { regression coefficient }\end{array}$ & $\begin{array}{l}\text { 95\% confidence } \\
\text { interval }\end{array}$ \\
\hline Coverage & 0.41795 & $(0.38181,0.45409)$ \\
Take-up proportion & 0.36715 & $(0.33100,0.40329)$ \\
Adherence & 0.00095 & $(-0.03520,0.03709)$ \\
Detection threshold & -0.47861 & $(-0.51475,-0.44247)$ \\
Target level & 0.34027 & $(0.30413,0.37642)$ \\
\hline
\end{tabular}

inhibit the inflow of local and foreign individuals with malaria infections sourced elsewhere. Successful implementation of this strategy requires among other things, decisions on when to conduct the campaign, the choice of diagnostic tool and drug and the level of resources and man-power available. Silal et al. used a population level transmission model for Mpumalanga to show that FSAT conducted at the Mpumalanga-Maputo border over the peak of the season only is not as effective in decreasing local infections because imported infections resume previous high levels as soon as FSAT is stopped [9]. Sustained decreases were predicted when FSAT was conducted at the border throughout the year.

The choice of diagnostic tool is a critical one for several reasons. Firstly, the tool should be highly sensitive to effectively screen and treat all infections. If a tool with a low to medium sensitivity is used, it is likely that subpatent infections will be missed by FSAT and enter Mpumalanga to contribute to infectious reservoir and thus to onward transmission. Okell et al. estimated that in very low prevalence settings, sub-patent infections comprise 
$70-80 \%$ of all malaria infections and are responsible for $20-50 \%$ of all human-to-mosquito infections [54]. Without addressing these sub-patent infections, it is likely that these low density infections will sustain malaria transmission [55]. Secondly, the diagnostic tool should take into account existing man-power and resources. Some tools such as qPCR require specialised equipment and highly trained operators while other tools like RDTs and LAMP have protocols that require minimal instrumentation and expertise [49]. Thirdly, the processing time of the tools will directly impact the usefulness of the tool in FSAT. Tools with long turnaround times are not feasible as it is unlikely that travellers would be willing to wait at a border-post for a result that takes a long time to process. In simulating the choice of diagnostic tool, the model predicted that microscopy and GPCR, though more sensitive than RDTs performed worse than LAMP and RDTs owing to the long processing times. LAMP may be an ideal tool for FSAT when the population of interest is able to wait for an hour to receive results, but this is most likely not the case for individuals passing through a border-post. The best performing tool was predicted to be a hypothetical RDT that had the standard processing time of 20 min with the sensitivity of LAMP. Modelling this hypothetical tool resulting in a capacity of 504 tests per week. The same target would be reached if increased resources resulted in nine LAMP tests being performed simultaneously instead of the baseline three tests.

From a provider perspective, the success of a FSAT strategy depends critically on the allocated capital and labour resources. Resources will influence the length of the FSAT campaign, the choice of tool and the labour assigned to the execution of the campaign. The model has predicted that processing a small proportion of individuals passing through the border results in small decreases in local infection. To optimize the impact of a FSAT campaign, the choice of tool and labour assigned to implement the tool should together seek to maximise the number of tests possible. From a participant perspective, the success of a FSAT campaign depends on the willingness to participate in the campaign and after a positive test result, the adherence of the participant to complete the drug regimen. The first line of malaria treatment in South Africa is a three day regimen of artemether-lumefantrine where only the first dose is supervised [56]. The issue of drug adherence may only be addressed adequately when a single dose cure of malaria is available. The model predicts that a high willingness to participate results in substantially larger decreases in local infections. One method to guarantee participation is to make the FSAT campaign mandatory. This approach would most likely require extensive resources to cope with the workload and enable efficient passing through the border, but may also be against the ethos of the South African and Mozambican governments. Yet even with mandatory FSAT, sub-patent infections may be missed depending on the screening tool employed. On the other hand, the model predicted that MDA at a low coverage in place of FSAT leads to large decreases in local infections as low sensitivity of screening tools is no longer an issue. Given recent estimates that $70-80 \%$ of all infections in a low transmission setting are sub-patent, MDA at the border becomes a suitable intervention [54]. An alternative way to view MDA at border entry points, is mandatory prophylaxis for travellers. Many countries require proof of vaccinations against yellow fever, typhoid, influenza and other diseases and infections. Proof of recent malaria prophylaxis can then effectively become a "lower cost" mass drug administration campaign for all travellers (local and foreign) travelling from a malaria-endemic country. If this becomes policy, the MDA campaign is effectively extended to all ports of entry into a country, not just the few selected for a traditional MDA/FSAT campaign. A 2003 study on Travellers' Knowledge, Attitudes and Practices at Johannesburg's O.R. Tambo International Airport revealed that $74 \%$ of respondents to the malaria questionnaire were carrying antimalarials in the form of prophylaxis or standby emergency treatment [57].

This is the first detailed FSAT study in South Africa and Mpumalanga. A lack of data on border crossings has resulted in the need to estimate migration rates from the transmission data and perform a sensitivity analysis on the results (Additional file 1). Future work includes migration data as it becomes available, extending the model to Southern Africa and adding an economic cost component to the FSAT IBM model in an attempt to optimize the impact on local infections based on a suite of potential diagnostic tools and the resources required to implement them.

\section{Conclusion}

Malaria incidence and related mortality has declined since 2002 to a point where South Africa is in the preelimination phase $(<5$ cases per 1,000$)$. In this time the proportion of annual imported cases has increased from $39 \%$ in 2002 to $87 \%$ in 2012 . The reduction of imported cases will be vital to any future malaria control or elimination strategy. Mathematical modelling has been used in this paper to estimate the impact of FSAT at a border control point under a variety of scenarios, as a means to reduce the inflow of imported infections in an environment where imported cases far exceed local cases. In this manner, mathematical modelling of FSAT may be used to inform a strategy with a strong regional focus aimed at interrupting local transmission so that malaria elimination may one day become a reality. 


\section{Additional file}

Additional file 1: Mathematical model description. Additional file contains the model description, model equations and additional information on the data-fitting process.

\section{Authors' contributions}

SPS conceived the study, performed the mathematical model development and analysis and wrote the paper. SPS and LJW conceptualized the mathematical model and analysis. FL, KIB and LJW reviewed the manuscript extensively. All authors read and approved the final manuscript.

\section{Author details}

1 Department of Statistical Sciences, University of Cape Town, Rondebosch, Cape Town 7700, South Africa. ${ }^{2}$ Division of Clinical Pharmacology, Department of Medicine, University of Cape Town, Observatory, Cape Town 7925, South Africa. ${ }^{3}$ Mahidol-Oxford Tropical Medicine Research Unit, Mahidol University, Bangkok, Thailand. ${ }^{4}$ Nuffield Department of Clinical Medicine, Centre for Tropical Medicine, Churchill Hospital, University of Oxford, Oxford, UK.

\section{Acknowledgements}

We are grateful to the Malaria Elimination Programme of the Department of Health in Mpumalanga, South Africa for the provision of data and are particularly grateful to Aaron Mabuza and Gerdalize Kok from the Malaria Elimination Programme and John Frean and Jaishree Raman from the National Institute for Communicable Diseases for their support. This material is based upon work supported financially by the National Research Foundation in South Africa. We are grateful to the National Research Foundation in South Africa for financial support. Any opinion, findings and conclusions or recommendations expressed in this material are those of the authors and therefore the NRF does not accept any liability in regard thereto. Mahidol-Oxford Tropical Medicine Research Unit is funded by the Wellcome Trust.

\section{Complaince with ethical guidelines}

\section{Competing interests}

The authors declare that they have no competing interests.

Received: 29 August 2014 Accepted: 28 June 2015

Published online: 12 July 2015

\section{References}

1. The malERA Consultative Group on Basic Science and Enabling (2011) A research agenda for malaria eradication: basic science and enabling technologies. Plos Med 8(1). Available from: http://www.plosmedicine. org/article/info\%3Adoi\%2F10.1371\%2Fjournal.pmed.1000399

2. The malERA Consultative Group on Diagnoses (2011) A research agenda for malaria eradication: diagnoses and diagnostics. PloS Med 8(1). Available from: http://www.plosmedicine.org/article/ info\%3Adoi\%2F10.1371\%2Fjournal.pmed.1000396

3. The malERA Consultative Group on Drugs (2011) A research agenda for malaria eradication: drugs. PloS Med 8(1). Available from: http:// www.plosmedicine.org/article/info\%3Adoi\%2F10.1371\%2Fjournal. pmed.1000402

4. The malERA Consultative Group on Modeling (2011) A research agenda for malaria eradication: modeling. PloS Med 8(1). Available from: http:// www.plosmedicine.org/article/info\%3Adoi\%2F10.1371\%2Fjournal. pmed.1000403

5. The malERA Consultative Group on Vector Control (2011) A research agenda for malaria eradication: vector control. PloS Med 8(1). Available from: http://www.plosmedicine.org/article/ info\%3Adoi\%2F10.1371\%2Fjournal.pmed.1000401

6. Moonen B, Cohen JM, Snow RW, Slutsker L, Drakeley C, Smith DL et al (2010) Operational strategies to achieve and maintain malaria elimination. Lancet 376(9752):1592-603. Available from: http://www.thelancet. com/journals/lancet/article/PIIS0140-6736(10)61269-X/fulltext
7. (2007) Malaria elimination. A field manual for low and moderate endemic countries. World Health Organisation, Geneva. Available from: http:// www.who.int/malaria/publications/atoz/9789241596084/en/

8. Silal SP, Little F, Barnes KI, White LJ (2014) Towards malaria elimination in Mpumalanga, South Africa: a population-level mathematical modeling approach. Malar J 3(297). Available from: http://www.malariajournal.com/ content/pdf/1475-2875-13-297.pdf

9. Silal SP, Little F, Barnes KI, White LJ (2015) Hitting a moving target: a model for malaria elimination in the presence of population movement. PLoS One (Under Review)

10. Silal SP, Barnes KI, Kok G, Mabuza A, Little F (2013) Exploring the seasonality of reported treated malaria cases in Mpumalanga, South Africa. PLoS One 8(10):e76640. Available from: http://www.plosone.org/article/ info\%3Adoi\%2F10.1371\%2Fjournal.pone.0076640

11. Maharaj R, Raman J, Morris N, Moonasar D, Durrheim DN, Seocharan I et al (2013) Epidemiology of malaria in South Africa: From control to elimination. S Afr Med J 103(10):779-783. Available from: http://www.samj.org. za/index.php/samj/article/view/7441/5461

12. Moonasar D, Nuthulaganti T, Kruger PS, Mabuza A, Rasiswi ES, Benson FG et al (2012) Malaria control in South Africa 2000-2010: beyond MDG6. Malar J 11(1):294. Available from: http://www.malariajournal.com/ content/11/1/294

13. Ngomane L, de Jager C (2012) Changes in malaria morbidity and mortality in Mpumalanga Province, South Africa (2001-2009): a retrospective study. Malar J 11(1):19. Available from: http://www.malariajournal.com/ content/11/1/19

14. Govere J, Durrheim D, Coetzee M, Hunt RH (2001) Malaria in Mpumalanga, South Africa, with special reference to the period 1987-1999. S Afr J Sci 97:55-58

15. Sharp BL, le Sueur D (1996) Malaria in South Africa-the past, the present and selected implications for the future. S Afr Med J 86(1):83-90. Available from: http://www.ncbi.nlm.nih.gov/pubmed/8685790

16. Sharp B, Craig MH, Mnzava A, Curtis B, Maharaj R, Kleinschmidt I (2001) Review of malaria in South Africa. Health Systems Trust, Westville

17. Blumberg L, Frean J (2007) Malaria control in South Africa - and successes, vol 97. http://www.samj.org.za/index.php/samj/article/view/304. S Afr Med J (11):1193

18. Sharp BL, Kleinschmidt I, Streat E, Maharaj R, Barnes KI, Durrheim DN et al (2007) Seven years of regional malaria control collaboration-Mozambique, South Africa and Swaziland. Am J Trop Med Hyg. 76(1):42-47

19. Lubombo Spatial Development Initiative; 2014 [cited 05/03/14]. Available from: http://www.malaria.org.za/lsdi/home.html

20. President's Malaria Initiative (2013) Mozambique Malaria Operational Plan Financial Year: 2013. President's Malaria Initiative

21. Mandal S, Sarkar RR, Sinha S (2011) Mathematical models of malaria-a review. Malar J 10(1):202. Available from: http://www.malariajournal.com/ content/10/1/202

22. Vittorini P, di Orio F (2013). In: Mohamad MS, Nanni L, Rocha MP, Fdez-Riverola F (eds) 7th international conference on practical applications of computational biology and bioinformatics. Vol. 222 of advances in intelligent systems and computing. Heidelberg: Springer International Publishing. Available from: http://link.springer. com/10.1007/978-3-319-00578-2

23. Sattenspiel L, Lloyd A (2009) The geographic spread of infectious diseases: models and applications. Princeton University Press, Princeton. Available from: http://books.google.com/ books?id=jtGP_qwD1MgC\&pgis=1

24. Ariey F, Duchemin JB, Robert V (2003) Metapopulation concepts applied to falciparum malaria and their impacts on the emergence and spread of chloroquine resistance. Infect Genet Evol 2(3):185-92. Available from: http://www.ncbi.nlm.nih.gov/pubmed/12797980

25. Oluwagbemi OO, Fornadel CM, Adebiyi EF, Norris DE, Rasgon JL (2013) ANOSPEX: a stochastic, spatially explicit model for studying Anopheles metapopulation dynamics. PLoS One 8(7). Available from: http://www.plosone.org/article/info:doi/10.1371/journal. pone.0068040\#pone-0068040-g004

26. Le Menach A, McKenzie FE, Flahault A, Smith DL (2005) The unexpected importance of mosquito oviposition behaviour for malaria: non-productive larval habitats can be sources for malaria transmission. Malar J 4(1):23. Available from: http://www.malariajournal.com/content/4/1/23 
27. Smith DL, Dushoff J, McKenzie FE (2004) The risk of a mosquito-borne infection in a heterogeneous environment. PLoS Biol 2(11). Available from: http://dx.plos.org/10.1371/journal.pbio.0020368

28. Arino J, Ducrot A, Zongo P (2012) A metapopulation model for malaria with transmission-blocking partial immunity in hosts. J Math Biol 64(3):423-448. Available from: http://www.ncbi.nlm.nih.gov/ pubmed/21442182

29. Zorom M, Zongo P, Barbier B, Somé B (2012) Optimal control of a spatiotemporal model for Malaria: synergy treatment and prevention. J Appl Math

30. Auger P, Kouokam E, Sallet G, Tchuente M, Tsanou B (2008) The RossMacdonald model in a patchy environment. Math Biosci 216(2):123-131. Available from: http://www.ncbi.nlm.nih.gov/pubmed/18805432

31. Rodriguez DJ, Torres-Sorando L (2001) Models of infectious diseases in spatially heterogeneous environments. Bull Math Biol 63(3):547-571. Available from: http://www.ncbi.nlm.nih.gov/pubmed/11374305

32. Okell LC, Griffin JT, Kleinschmidt I, Hollingsworth TD, Churcher TS, White MJ et al (2011) The potential contribution of mass treatment to the control of Plasmodium falciparum malaria. PLoS One 6(5). Available from: http://www.plosone.org/article/info\%3Adoi\%2F10.1371\%2Fjournal. pone.0020179

33. Griffin JT, Hollingsworth TD, Okell LC, Churcher TS, White M, Hinsley W et al (2010) Reducing Plasmodium falciparum malaria transmission in Africa: a model-based evaluation of intervention strategies. PloS Med 7(8). Available from: http://www.ncbi.nlm.nih.gov/pubmed/20711482

34. Smith T, Maire N, Ross a, Penny M, Chitnis N, Schapira A et al (2008) Towards a comprehensive simulation model of malaria epidemiology and control. Parasitol 135(13):1507-1516. Available from: http://www. ncbi.nlm.nih.gov/pubmed/18694530

35. Maire N, Smith T, Ross A, Owusu-Agyei S, Dietz K, Molineaux L (2006) A model for natural immunity to asexual blood stages of Plasmodium falciparum malaria in endemic areas. Am J Trop Med Hyg 75(2):19-31. Available from: http://www.ajtmh.org/content/75/2_suppl/19.abstract

36. Crowell V, Briët OJT, Hardy D, Chitnis N, Maire N, Di Pasquale A et al (2013) Modelling the cost-effectiveness of mass screening and treatment for reducing Plasmodium falciparum malaria burden. Malar J 12(1):4. Available from: http://www.malariajournal.com/content/12/1/4

37. Maude RJ, Pontavornpinyo W, Saralamba S, Aguas R, Yeung S, Dondorp AM et al (2009) The last man standing is the most resistant: eliminating artemisinin-resistant malaria in Cambodia. Malar J 8. Available from: http://www.malariajournal.com/content/8/1/31

38. White LJ, Maude RJ, Pongtavornpinyo W, Saralamba S, Aguas R, Van Effelterre T et al (2009) The role of simple mathematical models in malaria elimination strategy design. Malar J 8:212. Available from: http://www. malariajournal.com/content/8/1/212

39. Craig MH, Snow RW, le Sueur D (1999) A climate-based distribution model of malaria transmission in Sub-Saharan Africa. Parasitol Today 15(3):105-111. doi:10.1016/S0169-4758(99)01396-4

40. Montosi E, Manzoni S, Porporato A, Montanari A (2012) An ecohydrological model of malaria outbreaks. Hydrol Earth Syst Sci. Aug, 16(8):27592769. Available from: http://www.hydrol-earth-syst-sci.net/16/2759/2012/ hess-16-2759-2012.html

41. Coleman M, Coleman M, Mabuza AM, Kok G, Coetzee M, Durrheim DN (2009) Using the SaTScan method to detect local malaria clusters for guiding malaria control programmes. Malar J 8(1):68. Available from: http://www.malariajournal.com/content/8/1/68

42. Koella JC, Antia R (2003) Epidemiological models for the spread of antimalarial resistance. Malar J 2(3). Available from: http://www.malariajournal.com/content/2/1/3

43. Cleveland RB (1990) STL: a seasonal-trend decomposition procedure based on LOESS. J Off Stat 6(1). Available from: http://cs.wellesley.edu/ cs315/Papers/stl\%20statistical\%20model.pdf

44. Kennedy J, Eberhart R Particle swarm optimization. In: Proceedings of ICNN'95-international conference on neural networks. vol 4. IEEE, pp 1942-1948. Available from: http://ieeexplore.ieee.org/articleDetails. jsp?arnumber $=488968$

45. Eberhart R, Kennedy J (1995) A new optimizer using particle swarm theory. In: MHS'95. Proceedings of the sixth international symposium on micro machine and human science. IEEE, pp 39-43. Available from: http://ieeexplore.ieee.org/articleDetails.jsp?arnumber $=494215$

46. R Core Group (2013) [cited 2013-12-20]. Available from: http://www.rproject.org
47. Zambrano-Bigiarini M, Rojas R (2013) A model-independent Particle Swarm Optimisation software for model calibration. Environ Model Softw 43:5-25. doi: 10.1016/j.envsoft.2013.01.004

48. Zambrano-Bigiarini M, Rojas R (2013) hydroPSO: Particle Swarm Optimisation, with focus on environmental models. R package version 0.3-3-for new features, see the 'NEWS' file (on CRAN, rforge or the package source). Available from: http://www.rforge.net/hydroPSO, http://cran.r-project. org/web/packages/hydroPSO

49. Grueninger $\mathrm{H}$, Hamed K (2013) Transitioning from malaria control to elimination: the vital role of ACTs. Trends Parasitol 29(2):60-4. Available from:

50. DHA Media Release (2005) South Africa and Mozambique sign a Visa Waiver Agreement. Department of Home Affairs, Pretoria, South Africa

51. Barnes KI, Durrheim DN, Little F, Jackson A, Mehta U, Allen E et al (2005) Effect of artemether-lumefantrine policy and improved vector control on malaria burden in KwaZulu-Natal, South Africa. PloS Med 2(11):e330

52. von Seidlein $L$ The failure of screening and treating as a malaria elimination strategy. PloS Med. (1). Available from: http://dx.plos.org/10.1371/ journal.pmed.1001595

53. Halliday KE, Okello G, Turner EL, Njagi K, Mcharo C, Kengo J et al (2014) Impact of intermittent screening and treatment for malaria among school children in Kenya: a cluster randomised trial. PloS Med 11(1):e1001594. Available from: http://dx.plos.org/10.1371/journal. pmed.1001594

54. Okell LC, Bousema T, Griffin JT, Ouédraogo AL, Ghani AC, Drakeley CJ (2012) Factors determining the occurrence of submicroscopic malaria infections and their relevance for control. Nat Commun 3:1237. doi:10.1038/ncomms2241

55. Mosha JF, Sturrock HJW, Greenhouse B, Greenwood B, Sutherland CJ, Gadalla N et al (2013) Epidemiology of subpatent Plasmodium falciparum infection: implications for detection of hotspots with imperfect diagnostics. Malar J 12(1):221. Available from: http://www.malariajournal.com/ content/12/1/221

56. (2011) National Malaria Elimination Strategy 2011-2018. South African National Department of Health, Pretoria

57. Toovey S, Jamieson A, Holloway M (2004) Travelers' knowledge, attitudes and practices on the prevention of infectious diseases: results from a study at Johannesburg International Airport. J Travel Med 11(1):16-22

58. (2012) Census 2011 Municipal report Mpumalanga. Statistics South Africa. Available from: http://www.statssa.gov.za/Census2011/Products/ MP_Municipal_Report.pdf

59. Zacarias OP, Andersson M et al (2010) Mapping malaria incidence distribution that accounts for environmental factors in Maputo ProvinceMozambique. Malar J. 9:79

60. (2013) Mortality and causes of death in South Africa, 2010: Findings from death notification. Pretoria: Statistics South Africa. Available from: http:// www.statssa.gov.za/publications/p03093/p030932010.pdf

61. Thomson D (1911) A research into the production, life and death of crescents in malignant tertian malaria, in treated and untreated cases, by an enumerative method; the leucocytes in malarial fever: a method of diagnosing malaria long after it is apparently cured. University Press

62. Eyles DE, Young MD (1951) The duration of untreated or inadequately treated Plasmodium falciparum infections in the human host. J Natl Malar Soc 10(4):327-336. Available from: http://www.ncbi.nlm.nih.gov/ pubmed/14908561

63. Collins WE, Jeffery GM (1999) A retrospective examination of sporozoiteand trophozoite-induced infections with Plasmodium falciparum: development of parasitologic and clinical immunity during primary infection. Am J Trop Med Hyg 61 (1 Suppl):4-19. Available from: http://www.ncbi. nlm.nih.gov/pubmed/10432041

64. Chitnis N, Hyman JM, Cushing JM (2008) Determining important parameters in the spread of malaria through the sensitivity analysis of a mathematical model. Bull Math Biol 70(5):1272-1296. Available from: http://www.ncbi.nlm.nih.gov/pubmed/18293044

65. Makanga M, Krudsood S (2009) The clinical efficacy of artemether/ lumefantrine (Coartem). Malar J 8(Suppl 1). Available from: http://www. malariajournal.com/content/8/S1/S5

66. Castillo-Riquelme M, Mclntyre D, Barnes K (2008) Household burden of malaria in South Africa and Mozambique: is there a catastrophic impact? Trop Med Int Health 13(1):108-122. Available from: http://www.ncbi.nlm. nih.gov/pubmed/18291009 
67. Hlongwana KW, Zitha A, Mabuza AM, Maharaj R (2011) Knowledge and practices towards malaria amongst residents of Bushbuckridge, Mpumalanga, South Africa. Afr J Prim Health Care Fam Med 3(1). Available from: http://www.phcfm.org/index.php/phcfm/article/view/257

68. Sama W, Owusu-Agyei S, Felger I, Dietz K, Smith T (2006) Age and seasonal variation in the transition rates and detectability of Plasmodium falciparum malaria. Parasitol 132(Pt 1):13-21. Available from: http://www. ncbi.nlm.nih.gov/pubmed/16393349

69. Filipe JAN, Riley EM, Drakeley CJ, Sutherland CJ, Ghani AC (2007) Determination of the processes driving the acquisition of immunity to malaria using a mathematical transmission model. PLoS Comput Biol 3(12):e255. Available from: http://dx.plos.org/10.1371/journal.pcbi.0030255

70. Griffin JT, Ferguson NM, Ghani AC (2014) Estimates of the changing age-burden of Plasmodium falciparum malaria disease in sub-Saharan Africa. Nat Commun 5. Available from: http://www.nature.com/ ncomms/2014/140211/ncomms4136/pdf/ncomms4136.pdf

71. Zaloumis S, Humberstone A, Charman SA, Price RN, Moehrle J, GamoBenito J et al (2012) Assessing the utility of an anti-malarial pharmacokinetic-pharmacodynamic model for aiding drug clinical development. Malar J 11(1). Available from: http://www.malariajournal.com/ content/11/1/303
72. Hendriksen ICE, White LJ, Veenemans J, Mtove G, Woodrow C, Amos B et al (2013) Defining falciparum-malaria-attributable severe febrile illness in moderate-to-high transmission settings on the basis of plasma PfHRP2 concentration. J Infect Dis 207(2):351-361. Available from: http://www. ncbi.nlm.nih.gov/pubmed/23136222

73. Starzengruber P, Fuehrer HP, Ley B, Thriemer K, Swoboda P, Habler VE et al (2013) High prevalence of asymptomatic malaria in south-eastern Bangladesh. Malar J 13:16. Available from: http://www.malariajournal. com/content/13/1/16

74. Hopkins H, Gonzalez IJ, Polley SD, Angutoko P, Ategeka J, Asiimwe C et al (2013) Highly sensitive detection of malaria parasitemia in a malariaendemic setting: performance of a new loop-mediated isothermal amplification kit in a remote clinic in Uganda. J Infect Dis 208(4):645-652. Available from: http://jid.oxfordjournals.org/content/early/2013/05/31/ infdis.jit184.full

75. Polley SD, Gonzalez IJ, Mohamed D, Daly R, Bowers K, Watson J et al (2013) Clinical evaluation of a loop-mediated amplification kit for diagnosis of imported malaria. J Infect Dis 208(4):637-644. Available from: http://jid.oxfordjournals.org/content/early/2013/04/30/infdis.jit183. abstract?keytype $=$ ref

\section{Submit your next manuscript to BioMed Central and take full advantage of:}

- Convenient online submission

- Thorough peer review

- No space constraints or color figure charges

- Immediate publication on acceptance

- Inclusion in PubMed, CAS, Scopus and Google Scholar

- Research which is freely available for redistribution

Submit your manuscript at

www.biomedcentral.com/submit
C Biomed Central 